\title{
Einleitung und Problemstellung
}

1902 stellten Richet und Portier den experimental-immuno-logischen BegrifF der Anaphylaxie auF. Kurz darauFschuF derKliniker v. Pir $7 / 8$ uet den BegrifF der Allergie, womit er die Andersartigkeit der Reaktion des Organismus beim Zweitkontakt mit einem Agens akzentuieren wollte. In der Folgezeit wurde der BegrifF der Allergie auf «Überempfindlichkeit schlechthin» ausgedehnt (Doerr), wo-bei man in Analogie zu den anaphylaktischen Erscheinungen die Antigen-Antikörperreaktion auch als pathogenetischen Grundvor-gang der Allergien postulierte. So faßten Weichardt (1905) und Wolff-Eisner (1906) den HeuschnupFen, sowie Meltzer (1910) das Bronchialasthma als anaphylaktische Phänomene auf. Merk-würdigerweise kann man aber im Serum von Asthmatikern und HeuschnupFenpatienten in vitro keine Antikörper nachweisen. Wohl gelingt dies im Prausnitz-Küstnerschen Versuch. Das Serum von Pollenallergikern muß also Substanzen enthalten, deren Reaktion mit dem Antigen man bis heute nur an den Zellen des kutan-vasculären Systems nachweisen kann. Schon Prausnitz und Küst-ner bezweiFelten deshalb, ob es sich bei diesen Substanzen um anaphylaktische Antikörper handle, zumal es ihnen nicht gelang, mit Serum eines Fischidiosynkrasikers durch HinzuFügen des spezifi-schen Antigens Praecipitine sowie Komplementbindung zu erzeu-gen, was anderseits mit dem Serum experimentell sensibilisierter Tiere gelingt.

Erst Coca grenzte 1923 solche menschlichen Idiosynkrasien von den Anaphylaxien ab. Diese spezíelle Art der Überempfind-lichkeitsreaktion nannte er «Atopie» (daneben stehend) und die Antikörper «Reagine» zur Unterscheidung von den anaphylaktischen Antikörpern. Unter dem OberbegrifF Atopie verstand er Krankheiten wie das Asthma bronchiale und den HeuschnupFen, die durch Folgende immunologische Kriterien charakterisiert seien: Prausnitz-Küstnersche Reaktion positiv, keine Komplementbin-

1

dung, keine placentare Ubertragung, relative Thermolabilität und positive intrakutane Sofortreaktion. Als weiteres Kriterium hob er die Erblichkeit hervor.

Die immunologische Wesensverschiedenheit von Atopie und Anaphylaxie wurde in der Folge von namhaften Allergologen be-stritten. So spricht z. B. Doerr vom falschen Prinzip Cocas und anderer, besonders amerikanischer Autoren, «die Fülle der klini-schen Bilder durch verschiedene Unterteilungen in ein System bringen zu wollen» und stellt ihnen «die konsequente Bemühung, das Gemeinsame aller klinischen Erscheinungen durch Gruppie-rung um das zentrale Phänomen der Anaphylaxie zu erfassen», als allein berechtigt gegenüber. Auch Kämmerer (1954) glaubt, daß mit der fortschreitenden Erkenntnis sich der unitaristische Stand-punkt schließlich als richtig erweise.

Ohne auf das Für und Wider des immunologischen Gegen-satzes zwischen Atopie und Anaphylaxie einzutreten, bleibt doch die Tatsache bestehen, daß beim Asthma und Heuschnupfen, wie auch beim Kinderekzem und der Neurodermitis disseminata, welche Wise und Sulzberger nachträglich dem atopischen Formenkreis zuordneten, familiäres Vorkommen « atopischer » Manifestationen -wenn auch kein konstantes - so doch ein häufiges Phänomen ist. In der vorliegenden Arbeit soil nun zu folgenden Fragen Stel-lung genommen werden: 
Welche Krankheiten gehören zum Formenkreis der Atopien?

Spielt der Erblichkeitsfaktor nur bei den familiärsn oder auch bei den nichtfamiliären Atopiefällen eine Rolle?

Wie sind die Erblichkeitsverhältnisse der Atopiker, die mit posi-tiven und derjenigen, die mit negativen Sofortreaktionen ein-hergehen?

Wie fallen die Intrakutanteste bei familiären Atopiefällen aus ?

Ist der Begriff Atopie gleichbedeutend mit hereditär prädispo-nierter Allergie ? Wenn nein, welches ist die Definition der Atopie?

Sind die Atopiker anfälliger als die übrigen Menschen für nicht-atopische allergische Krankheiten, wie Kontaktekzeme, Medi-kamentenidiosynkrasien und Urticaria?

Zeigen die Atopien eine Geschlechtsdisposition? Wenn j a, welche Bedeutung muß ihr beigemessen werden?

Zeigt der Atopiker eine spezielle Affinität zu einem der Kretsch-merschen Habitustypen ?

Welche Bedeutung kommt dem Genotypus bei den Atopien zu?

2

Weder die Allergielehre noch die Genetik haben sich mit die-sen Fragen eingehend beschäftigt.

Die erstere befaßte sich fast aus-schließlich mit der Antigen-Antikörperreaktion, während sich

die Genetik allzu verkrampft auf den Standpunkt stellte, daß bei die-sen Krankheitsbildern auch

die Heredität eine Rolle spiele.

Die Wechselbeziehungen zwischen Heredität und Reaginbil-dung werden einerseits populationsgenetisch, anderseits mit den Methoden der Zwillings- und Familienforschung untersucht. So richtet sich diese Arbeit sowohl an den Allergologen als auch an den Humangenetiker.

Die vorliegende Arbeit wurde im Frühjahr 1956 unter meinem damaligen Lehrer Prof. Dr. G. Miescher begonnen. Der glückliche Umstand wollte es, daß sein Nachfol-ger Prof. Dr. H. Storck die Arbeit nicht nur förderte, sondern durch neue Fragestellun-gen wesentlich zu ihrem Gelingen beigetragen hat. Beiden Lehrern bin ich zu besondc-rem Dank verpflichtet und verbunden.

Die Ergebnisse stellen das Resultat einer Teamarbeit dar. Die Herren Th. Alb-recht, P. Bovet, A. Haynal und insbesondere W. Klunker waren mir bei der Auf-arbeitung des populationsstatistischen, familien- und zwillingspathologischen Materials behilflich. Bei einzelnen mathematischen Fragen ließ ich mich durch Herrn Prof. Dr. phil. E. Batschelet in Basel beraten, wofür ich ihm bestens danke. Frl. C. FiLusführ-te die anthropologischen Messungen durch. Allen Mitarbeitern danke ich an dieser Stelle herzlich. Ich erhielt durch sie manche Anregung. Herrn Dr. med. G. Anders, Oberassistent am Zoologischen Institut der Universität Zurich (Direktor Prof. Dr. E. Hadorn) danke ich für die kritische Durchsicht des Manuskriptes. Dem Zeichner der Abbildungen und Stammbäume, Herrn stud. ing. H. Menzi, schulde ich für seine from-schöne und sorgfältige Arbeit Dank.

Ferner danke ich den praktizierenden Ärzten, die bereitwillig ihre medizínischen Akten zur Verfügung stellten.

Die kostspieligen Untersuchungen wären nicht möglich gewesen ohne die groß-zügige finanzielle Unterstützung von öffentlicher und privater Hand. Die populations-statistische Untersuchung wurde durch einen Kredit des Schweizerischen National-fonds zur Förderung der wissenschaftlichen Forschung ermöglicht. Die familienpatho-logischen Untersuchungen finanzierte die Fritz-Hoffmann-La Roche-Stiftung zur Förderung wissenschaftlicher Arbeitsgemeinschaften in der Schweiz. Für die anthropologischen und allergologischen 
Familienuntersuchungen stellte die Sandoz- Stiftung Basel die Mittel zur Verfügung. Dem Schweizerischen Nationalfonds und den privaten Stiftungen sei an dieser Stelle herzlich gedankt. Trotz dieser günstigen äußeren Umstände war die ganze Untersuchung nur möglich dank der vorbildlichen Mitarbeit von 1525 Kranken und mehr als 12000 Gesunden. Die vorliegende Arbeit hat den Beweis erbracht, daß unsere Bevölkerung der medizini-schen Forschung auch dann Interesse und Verständnis entgegenbringt, wenn sie keinen unmittelbaren Nutzen erhoffen darf. Ihr gebührt darum der spezielle Dank!

Dank dem Entgegenkommen der Redaktionskollegien von Acta Genetica et Statistica Medica und International Archives of Allergy and Applied Immunology wird die Arbeit einem größeren Leserkreis zugänglich gemacht. Schließlich danke ich Herrn Thomas Karger für die sorgfältige Drucklegung des vorliegenden Buches. 